\title{
Pain assessment and management in children in the postoperative period: A review of the most commonly used postoperative pain assessment tools, new diagnostic methods and the latest guidelines for postoperative pain therapy in children
}

\author{
Jakub Zieliński ${ }^{A-F}$, Monika Morawska-Kochman ${ }^{A-F}$, Tomasz Zatoński ${ }^{A-F}$ \\ Department of Otolaryngology, Head and Neck Surgery, Wroclaw Medical University, Poland \\ A - research concept and design; $\mathrm{B}$ - collection and/or assembly of data; $\mathrm{C}$ - data analysis and interpretation; \\ $\mathrm{D}$ - writing the article; $\mathrm{E}$ - critical revision of the article; $\mathrm{F}$ - final approval of the article
}

Address for correspondence

Jakub Zieliński

E-mail:zielinski.kuba@gmail.com

Funding sources

None declared

Conflict of interest

None declared

Received on June 24, 2019

Reviewed on August 14, 2019

Accepted on September 25, 2019

Published online on March 4, 2020

Cite as

Zieliński J, Morawska-Kochman M, Zatoński T. Pain assessment

and management in children in the postoperative period:

A review of the most commonly used postoperative pain assessment tools, new diagnostic methods and the latest guidelines for postoperative pain therapy in children. Adv Clin Exp Med. 2020;29(3):365-374. doi:10.17219/acem/112600

DOI

$10.17219 /$ acem $/ 112600$

Copyright

Copyright by Author(s)

This is an article distributed under the terms of the

Creative Commons Attribution 3.0 Unported (CC BY 3.0)

(https://creativecommons.org/licenses/by/3.0/)

\begin{abstract}
Pain is one of the most common complaints expressed by hospital patients and is the main reason they seek medical help. Pain is always subjective, so its severity should be assessed individually for each patient. The main issue with pain management in children is the difficulty involved in evaluating it. Numerous studies have developed tools that would allow for an accurate assessment of the intensity of pain in children in the postoperative period. Adequate postoperative pain assessment in pediatric patients may significantly improve their comfort and quality of life. Postoperative pain prolongs recovery and hospitalization; therefore, the severity of the pain should be part of a routine assessment. Whichever tool is applied to measure pain, it should take into account the child's age, language, ethnicity, and cognitive ability. There is no one universal method for pain assessment which is appropriate for every pediatric patient. This article provides a review of the available subjective methods of postoperative pain assessment, including new objective diagnostic methods and the latest guidelines for postoperative pain therapy in a group of pediatric patients.
\end{abstract}

Key words: pain, postoperative pain, pain treatment, pediatric 


\section{Introduction}

The main issue with pain management in children - especially young children - is the difficulty involved in evaluating it. When a patient's level of pain cannot be accurately assessed, effective analgesia cannot be prescribed. When children are not sufficiently treated for pain, stress hormones are released into their systems, resulting in increased catabolism, immunosuppression and hemodynamic instability.

Pain is defined by the International Association for the Study of Pain as an unpleasant sensory and emotional experience associated with actual or potential tissue damage, or described in terms of such damage, and is caused by pain stimuli (also known as nociceptive stimuli). Pain is induced in the appropriate receptors, the nociceptors, and then transmitted through nociceptive pathways to the central nervous system, by signals that trigger a cascade of changes in the somatosensory system. These changes increase the response to further stimuli, thus increasing the pain. ${ }^{1}$

Pain is one of the most common complaints experienced by hospital patients ${ }^{2}$ and is the main reason they seek medical help. Pain is always subjective, so its severity should be assessed individually for each patient. Pain consists of everything the patient describes as pain, regardless of the objective symptoms associated with it. A lack of verbal communication does not equate to a lack of pain sensation, so appropriate analgesic treatment may still be required. In 1992, the American Academy of Pediatrics and the American Pain Society issued a statement aimed at providing comprehensive treatment for pain and suffering in all children and adolescents, suggesting that attention should be focused on interdisciplinary treatment, including pharmacological, cognitive behavioral, psychological, and physical treatment. ${ }^{3}$ Compared to adult patients, it is more difficult to assess and treat pain in children, a fact which often results in insufficient analgesics being administered. The available literature documents the harmful physiological effects of pain on young patients $^{4,5}$ as well as the beneficial results of effective analgesia in children. ${ }^{6}$ The commonly available methods of assessing pain intensity are based on the patient's own account or depend on a clinical evaluation performed by medical personnel. It is necessary to increase the use of the available pain assessment tools and scales that allow for the most objective assessment of pain severity and the most effective analgesia possible.

\section{Description of current knowledge}

Numerous studies have developed tools that would allow for an accurate assessment of the intensity of pain in children in the postoperative period. In this review, the PubMed database was queried with the keywords 'postoperative', 'pain assessment' and 'pain scale', searching for articles published between 1950 and 2019. In total, 8,769 articles were found. After filtering for age from infancy to 18 years, 1,944 articles were left. Articles in any language other than English were not considered. An evaluation of the titles and abstracts excluded a further 1,666 studies which - despite the age range filter - also referred to adult patients and to scales used in a period other than the postoperative one, leaving 278 articles eligible for review. A total of 10 distinct common pain scales were identified. All scales were used in the postoperative period in children. A summary of the scales is provided in Table 1.

Table 1. Most often used pain scales from the literature which meet the search criteria

\begin{tabular}{|c|c|c|c|}
\hline Acronym & Age range & First reference (author) & Number of citations \\
\hline CHEOPS & $1-7$ years & McGrath PJ et al. ${ }^{8}$ & 33 \\
\hline FLACC & 2 months -7 years & Merkel S et al. ${ }^{11}$ & 26 \\
\hline CHIPPS & $0-5$ years & Büttner W et al..$^{14}$ & 9 \\
\hline OPS and MOPS & 8 months -13 years & $\begin{array}{l}\text { Broadman LM et al.22 } \\
\text { Wilson GAM et al. } .^{24}\end{array}$ & 23 \\
\hline Poker Chip Tool & from 3 years & Hester $\mathrm{N}$ et al. ${ }^{27}$ & 4 \\
\hline Oucher Scale & $3-12$ years & Beyer JE et al..$^{35}$ & 10 \\
\hline Wong-Baker FACES ${ }^{\circledR}$ Pain Rating Scale & from 3 years & $\begin{array}{l}\text { Whaley L et al. }{ }^{30} \\
\text { Wong DL et al. } .^{31}\end{array}$ & 34 \\
\hline FPS-R & from 4 years & Hicks CL et al. ${ }^{39}$ & 31 \\
\hline VAS & from 5 years & Hayes $\mathrm{MH}$ et al. ${ }^{45}$ & 92 \\
\hline NRS & from 8 years & Jensen MP et al. ${ }^{49}$ & 16 \\
\hline
\end{tabular}

CHEOPS - Children's Hospital of Eastern Ontario Pain Scale; FLACC - Face, Legs, Activity, Cry and Consolability; CHIPPS - Children and Infants Postoperative Pain Scale; OPS/MOPS - Objective Pain Scale/Modified Objective Pain Scale; FPS-R - Faces Pain Scale - Revised; VAS - Visual Analogue Scale; NRS - Numeric Rating Scale. 


\section{Pain assessment tools: Evaluation of pain according to the patient's age}

As a result of growth differences, the expression of pain is different in each age group.

\section{Infants and toddlers}

Self-assessment scales do not apply to the youngest group of patients due to their inability to communicate verbally. According to Pawar and Garten, ${ }^{6}$ the symptoms of pain in this age group include body rigidity, facial overexpression (furrowed eyebrows and exaggerated eye closure), loud crying, sleep disorders, resistance, and shifting the painful part of the body away from touch. Toddlers may do any of the following: exhibit verbal aggression, cry because of the pain, show regressive behavior, repel the harmful stimuli, or defend the part of the body exposed to pain.

Behavioral parameters - even non-specific ones - can be used in conjunction with physiological parameters, such as heart rate, blood pressure or palm sweating. A number of behavioral scales have been developed which include these symptoms. ${ }^{7}$ The most commonly used ones are the Children's Hospital of Eastern Ontario Pain Scale (CHEOPS), ${ }^{8-10}$ Face, Legs, Activity, Cry and Consolability (FLAAC) $)^{9,11-13}$ and the Children and Infants' Postoperative Pain Scale (CHIPPS). ${ }^{14-17}$

\section{Children's Hospital of Eastern Ontario Pain Scale}

The CHEOPS is a behavioral scale used to assess postoperative pain in young children aged 1-7 years. According to this scale, pain assessment should be performed every $3 \mathrm{~h}, 15-20 \mathrm{~min}$ after intravenous analgesics and 30-45 min after oral or rectal analgesics. The child's behavior is assessed according to the criteria shown below (Table 2);

Table 2. The Children's Hospital of Eastern Ontario Pain Scale (CHEOPS)

\begin{tabular}{|c|c|c|c|}
\hline Parameter & Criteria & Score & Definition \\
\hline \multirow{4}{*}{ Cry } & no cry & +1 & Child is not crying. \\
\hline & moaning & +2 & Child is moaning or quietly vocalizing silent cry. \\
\hline & crying & +2 & Child is crying, but the cry is gentle or whimpering. \\
\hline & scream & +3 & Child is in a full-lunged cry; sobbing; may be scored with complaint or without complaint. \\
\hline \multirow{3}{*}{ Facial } & smiling & 0 & Score only if definite positive facial expression. \\
\hline & composed & +1 & Neutral facial expression. \\
\hline & grimace & +2 & Score only if definite negative facial expression. \\
\hline \multirow{5}{*}{ Child verbal } & positive & 0 & Child makes any positive statements or talks about other things without complaint. \\
\hline & none & +1 & Child not talking. \\
\hline & other complaints & +1 & Child complains, but not about pain, e.g., 'I want to see mommy' or 'I am thirsty'. \\
\hline & pain complaints & +2 & Child complains about pain \\
\hline & both complaints & +2 & Child complains about pain and about other things, e.g., 'It hurts' and 'I want my mommy'. \\
\hline \multirow{6}{*}{ Torso } & neutral & +1 & Body (not limbs) is at rest; torso is inactive. \\
\hline & shifting & +2 & Body is in motion in a shifting or serpentine fashion. \\
\hline & tense & +2 & Body is arched or rigid. \\
\hline & shivering & +2 & Body is shuddering or shaking involuntarily. \\
\hline & upright & +2 & Child is in a vertical or upright position. \\
\hline & restrained & +2 & Body is restrained. \\
\hline \multirow{5}{*}{ Touch } & not touching & +1 & Child is not touching or grabbing at wound. \\
\hline & reach & +2 & Child is reaching for but not touching wound. \\
\hline & touch & +2 & Child is gently touching wound or wound area. \\
\hline & grab & +2 & Child is gently touching wound or wound area. \\
\hline & restrained & +2 & Child is grabbing vigorously at wound area. \\
\hline \multirow{5}{*}{ Legs } & neutral & +1 & Legs may be in any position but are relaxed; includes gentle swimming or separate-like movements. \\
\hline & squirm/kicking & +2 & Definitive uneasy or restless movements in the legs and/or striking out with foot or feet. \\
\hline & drawn up/tensed & +2 & Legs tensed and/or pulled up tightly to body and kept there. \\
\hline & standing & +2 & Standing, crouching or kneeling. \\
\hline & restrained & +2 & Child's legs are being held down. \\
\hline
\end{tabular}

Adapted from: McGrath PJ, Johnson G, Goodman JT, et al. CHEOPS: A behavioral scale for rating postoperative pain in children. Adv Pain Res Ther. 1985;9:395-402. Accessed February 8, 2019 with permission from Patrick McGrath. 
Table 3. Face, Legs, Activity, Cry and Consolability (FLAAC) scale

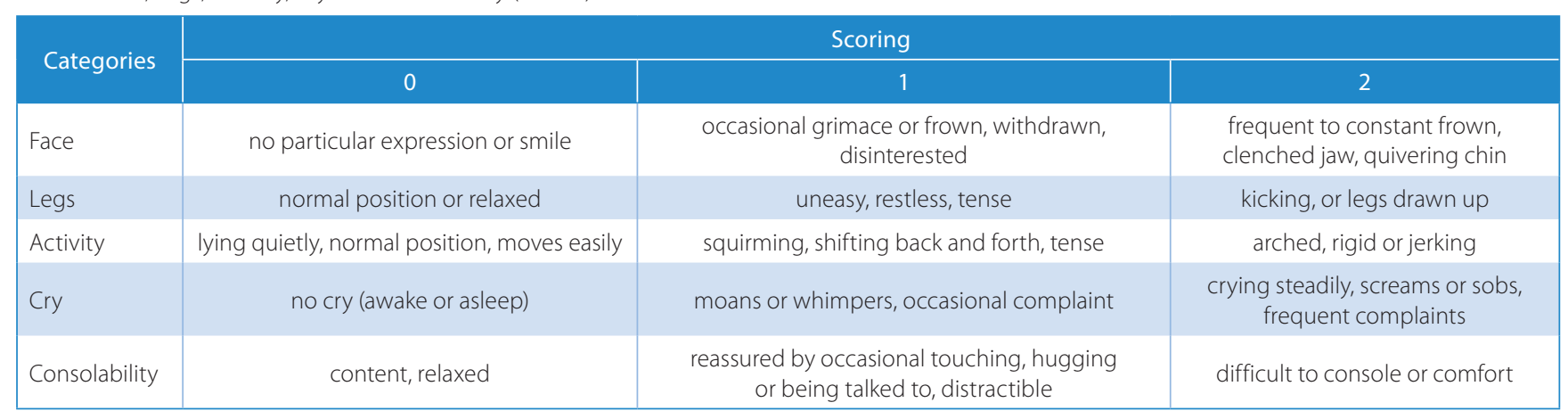

Merkel S, Voepel-Lewis T, Shayevitz S, Malviya S. The FLACC: A behavioral scale for scoring postoperative pain in young children. Pediatr Nurs. 1997;23(3): 293-297. Copyright ${ }^{\odot} 2002$, The Regents of the University of Michigan. All rights reserved.

Each of the 5 categories (F) Face; (L) Legs; (A) Activity; (C) Cry; (C) Consolability is scored 0-2, which results in a total score between 0 and 10.

the minimum score is 4 points and the maximum score is 13 points. A score $\geq 5$ should be considered for the administration of an analgesic, whilst a score $\geq 8$ should be interpreted as requiring the administration of an analgesic.

\section{Face, Legs, Activity, Cry and Consolability}

The FLAAC scale (Table 3) is a tool for assessing the intensity of postoperative pain in young children and infants or in children without contact, who are asleep, aged from 2 months to 7 years, with exposed body and limbs; the observation should last 2-5 min. Each parameter is evaluated on a scale from 0 to 2 ; the total score is interpreted as follows: 0 = relaxed and comfortable, $1-3=$ mild discomfort, $4-6=$ moderate pain, $7-10=$ severe discomfort/pain. A score of more than 3 points suggests the need for analgesics.

\section{Children and Infants' Postoperative Pain Scale}

The CHIPPS (Table 4) is intended to assess the intensity of postoperative pain in infants and children under the age of 5 years. The pain evaluation should be carried out within $15 \mathrm{~s}$. In the postoperative period, values from 0 to 3 points indicate that there is no pain, whilst a score $\geq 4$ points indicates the need for analgesics.

\section{COMFORT scale}

It is also necessary to emphasize the COMFORT scale, which is less frequently used in surgical wards due to the complexity of measuring blood pressure and heart rate. This scale is used primarily for patients in a critical care setting. The COMFORT ${ }^{18}$ scale is used to assess both behavioral and physiological elements in children. This scale has 8 indicators: alertness, calmness/agitation, respiratory response, physical movement, blood pressure, heart rate, muscle tone, and facial tension.

Each parameter is scored from 1 to 5 . The overall score is between 8 and 40 points. A score between 17 and 26 indicates adequate sedation and pain control. Values above 26 indicate that the patient is experiencing pain. Initially,
Table 4. Children and Infants Postoperative Pain Scale (CHIPPS)

\begin{tabular}{|l|c|c|}
\hline \multicolumn{1}{|c|}{ Item } & Structure & Points \\
\hline \multirow{2}{*}{ Crying } & none & 0 \\
& moaning & 1 \\
Facial expression & relaxed/smiling & 2 \\
& wry mouth & 0 \\
\hline Posture of the trunk & grimace (mouth and eyes) & 1 \\
& neutral & 2 \\
\hline Posture of the legs & rear up & 0 \\
& neutral, released & 1 \\
& kicking about & 0 \\
Motor restlessness & tightened legs & 1 \\
& nodere & 2 \\
\hline
\end{tabular}

Büttner W, Finke W. Analysis of behavioural and physiological parameters for the assessment of postoperative analgesic demand in newborns, infants and young children: A comprehensive report on 7 consecutive studies. Paediatr Anaesth. 2000;10(3):303-318.

the COMFORT scale was used to evaluate the level of sedation or distress and procedural pain. ${ }^{19,20}$ Currently it is also used in the postoperative period. ${ }^{21}$

\section{Preschoolers}

Children aged 3 to 7 years are able to describe the severity of their pain on an individual basis and grow increasingly expressive with age in describing the severity, location and value of pain. They can understand pain as punishment, they complain and refuse to cooperate with parents, a nurse, or a doctor, they try to push away harmful stimuli, they demand emotional support, and - as with younger patients - they may suffer from sleep disorders. ${ }^{6}$ At this age, both scales based on observation of the child and those that require the patient's self-assessment are used. The most commonly used scales are the Objective Pain Score (OPS) ${ }^{22,23}$ and the modified version of it, the Modified Objective Pain Scale (MOPS), ${ }^{24-26}$ the Poker Chip Tool (Pieces of Hurt Tool), ${ }^{27-29}$ the Wong-Baker FACES ${ }^{\circledR}$ Pain 
Rating Scale, ${ }^{30-34}$ the Oucher Scale, ${ }^{35-38}$ and the Faces Pain Scale - Revised (FPS-R). ${ }^{39-42}$

\section{Objective Pain Scale and Modified Objective Pain Scale}

The Objective Pain Scale (OPS) and the Modified Objective Pain Scale (MOPS) (Table 5) are used to evaluate both the physiological parameters of pain and the behavioral changes in children which accompany pain or discomfort after surgical procedures. Wilson and Doyle ${ }^{24}$ modified the OPS by substituting posture assessment for blood pressure in order to assess pain in children ranging in age from 8 months to 13 years. The MOPS can be used by a patient's parents, and the criterion 'holds injury site' could be substituted for the type of surgery performed. The minimum score is 0 and the maximum is 10 ; the higher the score, the greater the pain experience for the child.

Table 5. Modified Objective Pain Scale (MOPS)

\begin{tabular}{|l|c|c|}
\hline Criteria & Finding & Points \\
\hline \multirow{3}{*}{ Crying } & none & 0 \\
& consolable & 1 \\
Movement & not consolable & 2 \\
& none & 0 \\
Agitation & restless & 1 \\
& thrashing & 2 \\
\hline \multirow{3}{*}{ Posture } & asleep/calm & 0 \\
& mild & 1 \\
Verbal & hysterical & 2 \\
& normal & 0 \\
& flexed & 2 \\
& holds injury site & 0 \\
& complains/cannot localize & 1 \\
& complains/can localize & 2 \\
\hline
\end{tabular}

Wilson GAM, Doyle E. Validation of three pediatric pain scores for use by parents. Anaesthesia. 1996;51(11):1005-1007.

\section{Poker Chip Tool}

The Poker Chip Tool (Fig. 1) is based on using 4 red poker chips. In the beginning, the child is asked whether he/she has any pain right now. If the child replies 'no',
0 is recorded. If the child says 'yes', he/she is given 4 chips. The child selects the number of chips that reflects the intensity of his/her pain, where 0 chips indicate little pain and 4 chips indicate the worst pain. It is used to assess the severity of pain in children aged from 3 to 18 years. ${ }^{43}$

\section{The Wong-Baker FACES ${ }^{\circledast}$ Pain Rating Scale}

The Wong-Baker FACES ${ }^{\circledR}$ Pain Rating Scale (Fig. 2) represents a series of faces from a 0 -value happy face (which represents a lack of pain) to a 10-value crying face (which suggests the worst possible pain). On this basis, the patient chooses the face that best describes his/her level of pain.

\section{Oucher Scale}

The Oucher Scale (Fig. 3-5) is a combination of 2 separate scales: a photographic facial scale and a numerical scale from 0 to 10 . The photographic scale contains $6 \mathrm{im}-$ ages of the same child, whose expressions suggest different levels of pain. The advantage of this scale is that there are different ethnic versions, e.g., presenting examples for white, black and Hispanic children. A vertical numerical scale from 0 to 10 is adjacent to these photographs. A numerical scale can be used by children who can count up to at least 100 and who understand, e.g., that 77 is more than 43. Children who do not understand the digits should use only the photographic facial scale.

\section{Faces Pain Scale - Revised}

The revised Faces Pain Scale (FPS-R) (Fig. 6) has been adapted to the commonly used metrics from 0 to 10 on the basis of the Faces Pain Scale (FPS). ${ }^{44}$ It presents faces in a horizontal row, where the one on the left side indicates no pain and the one on the right side indicates the greatest possible pain. The researcher should explain to the child, 'These faces show how much something can hurt. This face [pointing to the face on the far left] shows no pain. The faces show more and more pain [pointing to each one from left to right] up to this one [pointing to the face on the far right], which shows very much pain.

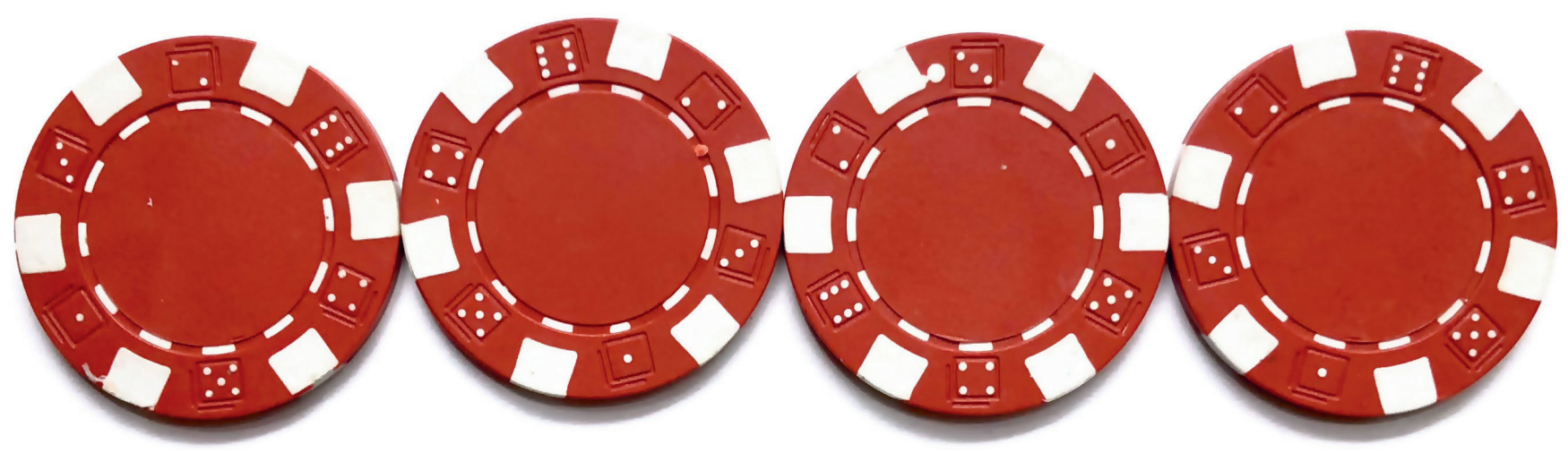

Fig. 1. The Poker Chip Tool (Pieces of Hurt Tool) 


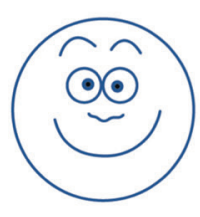

0

No

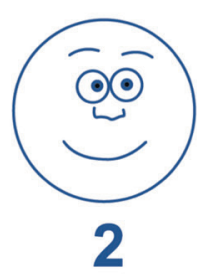

Hurts Little Bit

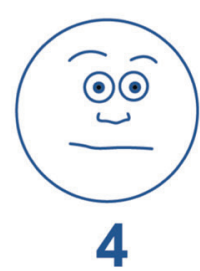

Hurts Little More

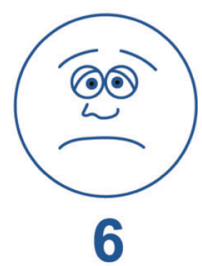

Hurts Even More

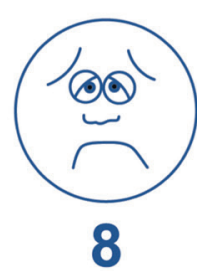

Hurts Whole Lot

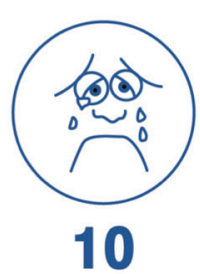

Hurts Worst

Fig. 2. Wong-Baker FACES ${ }^{\circledR}$ Pain Rating Scale

๑) 1983 Wong-Baker FACES Foundation. www.WongBaketFACES.org. Used with permission. Originally published in Whaley \& Wong's Nursing Care of Infants and Children. OElsevier Inc.

\section{DUGHER!}

10

9
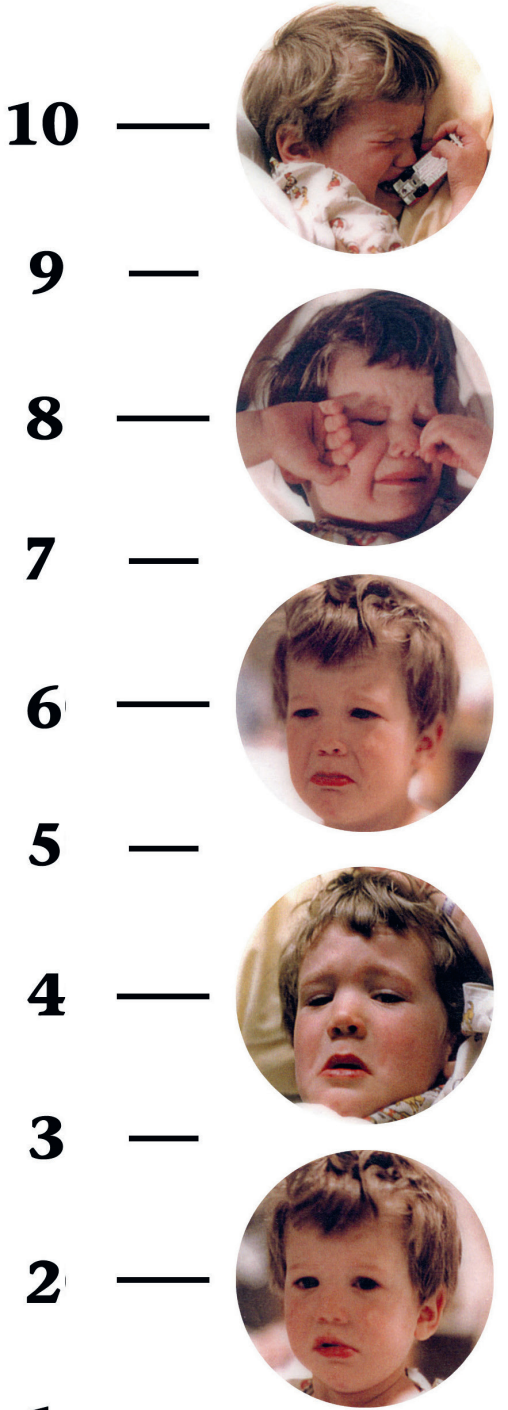

1

0

http://www.oucher.org

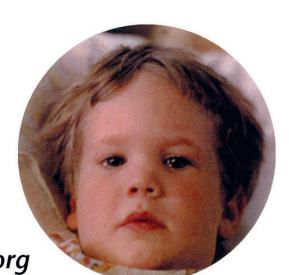

Fig. 3. Caucasian Oucher scale

\section{ELGHER!"}

10

9
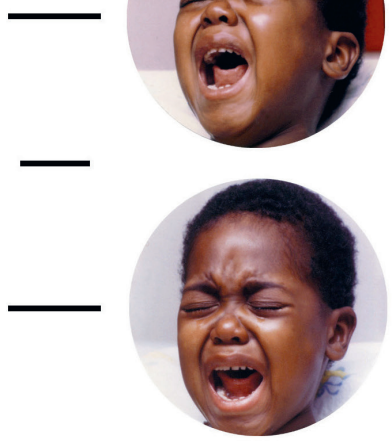

7

6

5
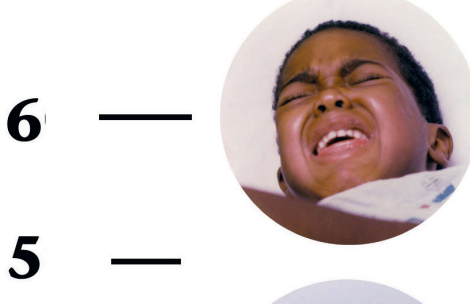

4
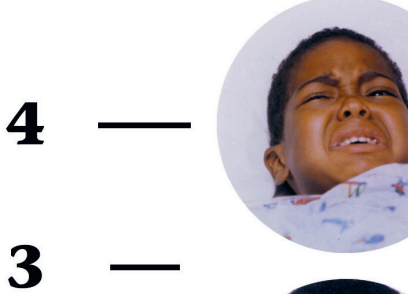

2
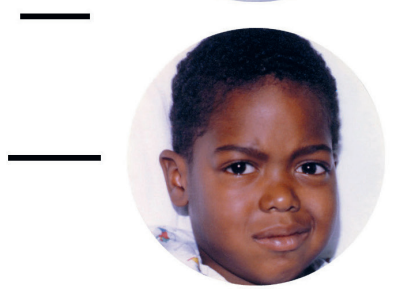

1

$\mathbf{0}$

http://www.oucher.org

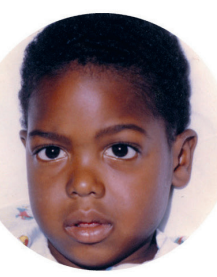

Fig. 4. African-American Oucher scale

\section{DUGHER!}
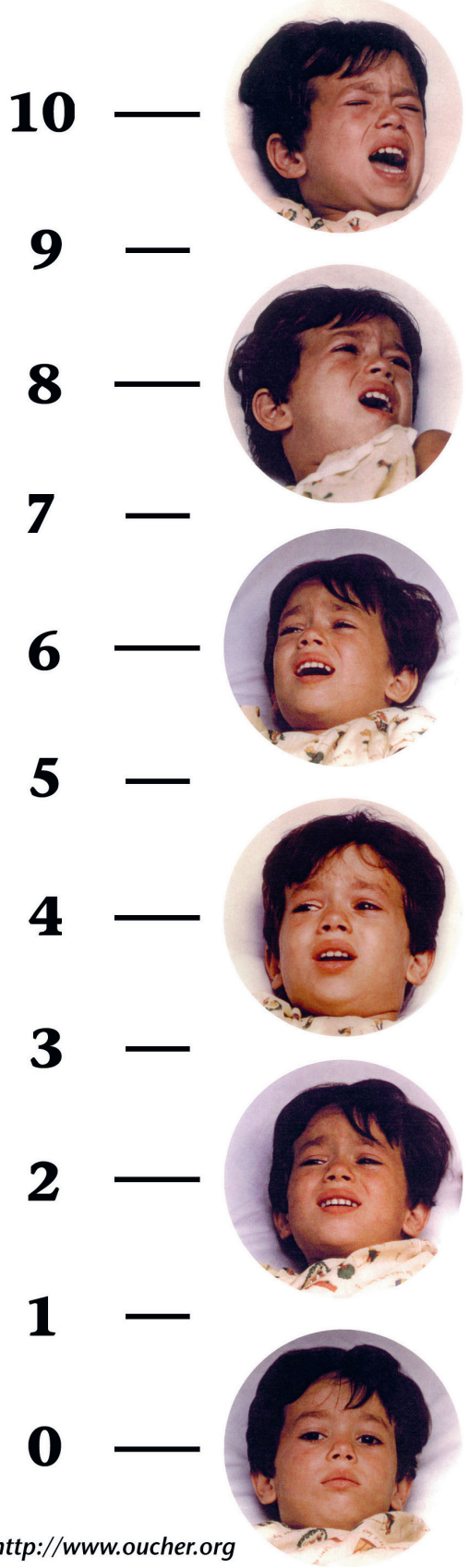

Fig. 5. Hispanic Oucher scale 

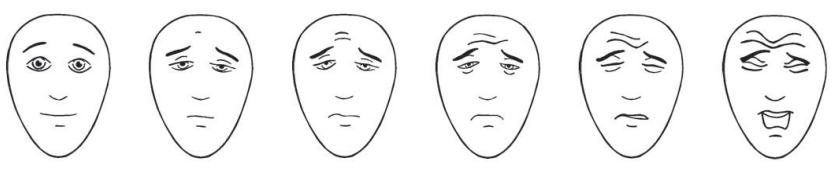

Fig. 6. Faces Pain Scale - Revised (FPS-R)

Point to the face that shows how much you hurt [right now].' Additionally, under each facial image are the numbers 0, 2, $4,6,8$, and 10 , ranging from the lowest to the highest intensity of pain, which can be seen on the back of the sheet and are not visible to the patient. The FPS-R is used to assess the intensity of the child's pain, which indicates how he or she feels; the researcher does not analyze the appearance of the patient's face or correlate it with the images.

\section{School-age children}

The verbalization of pain is common in this age group and is a great diagnostic facilitator. In addition, schoolage children may experience nightmares associated with pain, increased muscular tension or body rigidity, e.g., clenching their fists and teeth or wrinkling their forehead. Adolescents may deny pain in the presence of their peers, experience appetite disorders or show regressive behavior in the presence of family members. ${ }^{6}$

The most commonly used scales at this age include the Visual Analogue Scale (VAS), ${ }^{45-48}$ the Faces Pain Scale - Revised (FPS-R) ${ }^{39}$ and the Numeric Rating Scale (NRS). ${ }^{33,49-52}$ These are the gold standard for pain assessment.

\section{Visual Analogue Scale}

The VAS (Fig. 7) is a line that is typically $10 \mathrm{~cm}$ long, with markings ' 0 ' and ' 10 ' on opposite sides. Zero stands for no pain and 10 indicates very strong pain. The patient is asked to mark a line or to select a point on the scale to indicate the intensity of their pain. There are many versions of VAS in the literature, and the differences between them include units of measurement, e.g., centimeters or millimeters, length -10 or $15 \mathrm{~cm}$ - and whether the scale is shown as a vertical or horizontal line.

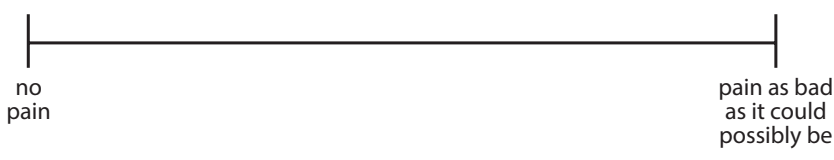

Fig. 7. Visual Analogue Scale (VAS)

\section{Numeric Rating Scale}

The Numeric Rating Scale (Fig. 8) is a segmented numerical version of the VAS scale in which patients chooses the integer from 0 to 10 which best reflects the severity of their pain. The assessment of pain intensity is as follows: no pain $=0$, mild pain $=1-3$, moderate pain $=4-6$, and severe pain $\geq 7$.

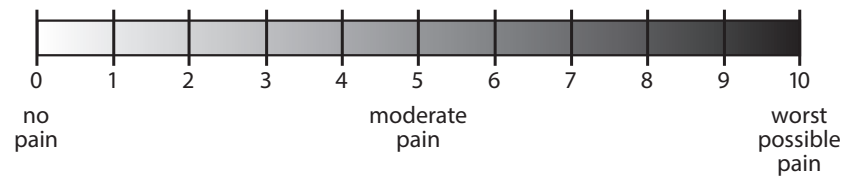

Fig. 8. Numeric Rating Scale (NRS)

\section{New diagnostic methods - towards an objective assessment of pain}

\section{Skin conductance}

Stimulation of the autonomic nervous system by nociceptive stimuli leads to skin conduction changes caused by the action of acetylcholine released in pain response to muscarinic receptors, with the subsequent release of sweat..$^{53}$ This reduces the electrical resistance of the skin and increases its conductivity. Fluctuations in skin amplitude and conductivity frequencies can then be used to assess pain. ${ }^{54}$ This is a nociceptive phenomenon which is not affected by the changes in heart rate, blood pressure or body temperature that might occur in response to a child's anxiety, e.g., hunger, fear of separation from parents or a foreign environment. A skin conductance algesimeter is used to measure the severity of pain in children and adults, unconscious patients, patients under general anesthesia or with verbal communication limitations. This type of pain assessment is therefore considered to be the most objective, ${ }^{55-57}$ despite the fact that the literature describes technical issues which may cause artifacts, such as electrode dislocation, wire stretching or excessive sweating by the patient. ${ }^{58} \mathrm{Mea}-$ suring skin conduction changes is an excellent pain detector, requiring further validation and clinical trials.

\section{Analgesia Nociception Index}

Analgesia Nociception Index (ANI $)^{59}$ is a non-invasive tool based on an analysis of fluctuations in heart rate, which combines electrocardiography and respiratory rate with high-frequency heart rate variability (HRV), in a frequency domain analysis. Heart rate variability is mediated primarily by changing the levels of parasympathetic and sympathetic outflow from the central nervous system to the sinoatrial node of the heart. The ANI monitor records the ECG signal continuously, enabling quantitative evaluation of respiratory variations in heart rate, which decreases during nociceptive stimulation. The ANI monitor was developed for patients over 2 years of age. Most of the ANI evaluation studies were performed in adult patients under general anesthesia or in the immediate postoperative period and showed that the ANI measurement was significantly correlated with the severity of pain. ${ }^{60}$ To date, very little data is available on the usefulness of ANI in children. 


\section{Newborn Infant Parasympathetic Evaluation Index}

Newborn Infant Parasympathetic Evaluation Index $(\mathrm{NIPE})^{61}$ provides an analysis of the parasympathetic response to a nociceptive stimulus. This indicator of nociception and analgesia effectiveness is also based on an algorithm for evaluating heart rate variability (HRV). As mentioned above, ANI was developed for adults and children over 2 years of age. Newborns and infants up to 2 years of age, due to the immaturity of the autonomic nervous system and the higher initial HR level, require a modified HRV analysis. The NIPE index is a modified version of ANI, and can reach values from 0 to 100. A score close to 100 indicates a higher level of patient comfort. Values below 50 indicate discomfort, stress or pain, which suggests a modification of the analgesic therapy. Few pediatric studies have yet validated this tool, although the NIPE index seems to be related to EDIN (Échelle Douleur Inconfort Nouveau-Né, neonatal pain and discomfort scale), for postoperative neonatal pain. ${ }^{62}$

\section{Principles of pain management in children}

It is important that children, regardless of their age, receive effective postoperative analgesia. The type and dosage of analgesics should be selected on the basis of scientific evidence, as well as standards and guidelines developed by local, national and international organizations. In this context, it is important to establish the standards of postoperative pain management in children that they expect from surgical procedures. The administration of basic analgesics (nonsteroidal anti-inflammatory drugs, paracetamol, etc.) intravenously, orally and rectally is crucial for pain management in children, and these drugs are to be found in most medical centers and hospitals around the world, even in resource-limited facilities. In addition, the effective use of basic analgesics has a significant impact on reducing the use of opioids, ${ }^{63,64}$ which are reserved for the intraoperative and early postoperative period, in conditions where adequate monitoring is provided and a continuous opioid infusion requires the availability of specially trained personnel $24 \mathrm{~h}$ a day.

Table 6. Dosage suggestions for systemic analgesia in children in the postoperative period

\begin{tabular}{|c|c|c|c|}
\hline Basic level & Intermediate level & Advanced level & Dosage suggestions \\
\hline \multicolumn{4}{|r|}{ Rectal NSAIDs } \\
\hline ibuprofen & ibuprofen & ibuprofen & $10 \mathrm{mg} \mathrm{kg}^{-1}$ every $8 \mathrm{~h}$ \\
\hline diclofenac & diclofenac & diclofenac & 1 mg kg-1 every $8 \mathrm{~h}$ \\
\hline naproxen & naproxen & naproxen & $5-7.5 \mathrm{mg} \mathrm{kg}^{-1}$ every $12 \mathrm{~h}$ \\
\hline \multicolumn{4}{|r|}{ Oral NSAIDs } \\
\hline ibuprofen & ibuprofen & ibuprofen & $10 \mathrm{mg} \mathrm{kg}^{-1}$ every $8 \mathrm{~h}$ \\
\hline diclofenac & diclofenac & diclofenac & 1 mg kg-1 every 8 h \\
\hline \multicolumn{4}{|r|}{ Intravenous NSAIDs } \\
\hline \multicolumn{2}{|c|}{-} & ketorolac & $\begin{array}{l}0.5-1 \mathrm{mg} \mathrm{kg}^{-1} \text { up to } 30 \mathrm{mg} \text { for a single intraoperative dose of } 0.15-0.2 \mathrm{mg} \mathrm{kg}^{-1} \text { ( } \max \\
10 \mathrm{mg} \text { ) every } 6 \mathrm{~h} \text { (short-term therapy, } \max 48 \mathrm{~h} \text { ) }\end{array}$ \\
\hline \multicolumn{2}{|c|}{-} & ketoprofen & $1 \mathrm{mg} \mathrm{kg}^{-1}$ every $8 \mathrm{~h}$ \\
\hline paracetamol & paracetamol & paracetamol & $\begin{array}{l}\text { Single loading dose in association with anesthesia; the higher dose is due to poor } \\
\text { bioavailability from rectal route of administration. }\end{array}$ \\
\hline \multicolumn{4}{|r|}{ Oral paracetamol } \\
\hline paracetamol & paracetamol & paracetamol & $10-15 \mathrm{mg} \mathrm{kg}^{-1}$ every $6 \mathrm{~h}$ \\
\hline \multicolumn{4}{|c|}{ Intravenous paracetamol } \\
\hline \multicolumn{2}{|c|}{-} & paracetamol & $\begin{array}{l}<10 \mathrm{~kg}: 7.5 \mathrm{mg} \mathrm{kg}^{-1} \\
>10 \mathrm{~kg}: 15 \mathrm{mg} \mathrm{kg}^{-1} \\
\text { Intravenous preparation: } 10 \mathrm{mg} \mathrm{mL}^{-1}\end{array}$ \\
\hline \multicolumn{4}{|c|}{ Intraoperative/postoperative intravenous metamizole } \\
\hline & - & metamizole & $\begin{array}{l}10-15 \mathrm{mg} \mathrm{kg}^{-1} \text { every } 8 \mathrm{~h} \text {. } \\
2.5 \mathrm{mg} \mathrm{kg}^{-1} \mathrm{~h}^{-1} \text { (continuous infusion following an intraoperative loading dose). } \\
\text { Due to the risk of agranulocytosis after long-term use metamizole is recommended } \\
\text { for short term postoperative use in a hospital setting only. }\end{array}$ \\
\hline
\end{tabular}

NSAIDs - nonsteroidal anti-inflammatory drugs.

Adapted with a permission from: Vittinghoff M, Lönnqvist PA, Mossetti V, et al. Postoperative pain management in children: Guidance from the pain committee of the European Society for Paediatric Anaesthesiology (ESPA Pain Management Ladder Initiative). Paediatr Anaesth. 2018;28(6):493-506. 
In 2018, the European Society for Paediatric Anaesthesiology (ESPA) Pain Committee published guidelines ${ }^{65}$ to improve postoperative pain management in children. Although these guidelines are primarily aimed at Europe, the authors of the guidelines hope that they can also be used in other countries around the world, and that postoperative pain therapy can be adapted based on the availability of medicines, national recommendations and drug registration rules in different countries. The ESPA consensus on postoperative pain management in children is presented in Table 6. Special precautions should be taken when prescribing opioids in patients with obstructive sleep apnea, due to the increased risk of ventilation disorders in the postoperative period. ${ }^{66}$

\section{Conclusions}

Adequate postoperative pain assessment in pediatric patients may significantly improve their comfort and quality of life. Postoperative pain prolongs recovery and hospitalization, ${ }^{67}$ so the severity of pain should be assessed routinely, using tools appropriate for the patient's age and disease. The research has been reviewed by selecting the scales most commonly used and validated in the postoperative period (Table 1). In order to establish simple criteria for scale selection, it seems most appropriate to categorize the patient's age into $\leq 5$ years and $>5$ years of age. For patients up to 5 years of age, the CHEOPS and FLACC scales should be used; they are behavioral scales and do not require self-assessment by the patient. For children over 5 years of age, who are able to describe the severity and intensity of their pain, it is recommended to use mainly pictorial scales - such as the ethnically differentiated Oucher scale, the Wong-Baker FACES ${ }^{\circledR}$ Pain Rating Scale, or the FPS-R - or the most commonly used VAS. Whichever tool is applied to measure pain, it should take into account the child's age, language, ethnicity, and cognitive ability. Without a doubt, more than one tool is required, because no individual scoring system will be appropriate for assessing pain in all children and in all contexts. Only by considering all of these parameters can an objective evaluation of the complex nature of pain be conducted. ${ }^{68}$

\section{ORCID iDs}

Jakub Zieliński (i) https://orcid.org/0000-0003-1747-2250

Monika Morawska-Kochman (1) https://orcid.org/0000-0001-6551-7535

Tomasz Zatoński (1) https://orcid.org/0000-0003-3043-4806

\section{References}

1. Woolf CJ. Neuronal plasticity: Increasing the gain in pain. Science. 2010;288(5472):1765-1768.

2. Mak WY, Yuen V, Irwin M, Hui T. Pharmacotherapy for acute pain in children: Current practice and recent advances. Expert Opin Pharmacother. 2011;12(6):865-881.

3. American Academy of Pediatrics. Psychosocial aspects of child and family health: The child as a witness. Pediatrics. 1992;89(3):513-515.
4. Grunau RE, Holsti L, Peters JWB. Long-term consequences of pain in human neonates. Semin Fetal Neonatal Med. 2006;11(4):268-275.

5. Mitchell A, Boss BJ. Adverse effects of pain on the nervous systems of newborns and young children: A review of the literature. $J$ Neurosci Nurs. 2002;34(5):228-236.

6. Pawar D, Garten L, Kopf A, Pathel NB. Pain management in children. In: Guide to Pain Management in Low-Resource Settings. Int Assoc Study Pain. 2010:255-267.

7. Ramelet A, Abu-Saad H, Rees N, McDonald S. The challenges of pain measurement in critically ill young children: A comprehensive review. Aust Crit Care. 2004;17(1):33-45.

8. McGrath PJ, Johnson G, Goodman JT, et al. CHEOPS: A behavioral scale for rating postoperative pain in children. Adv Pain Res Ther. 1985;9:395-402.

9. Suraseranivongse S, Santawat U, Kraiprasit K, Petcharatana S, Prakkamodom S, Muntraporn N. Cross-validation of a composite pain scale for preschool children within 24 hours of surgery. Br JAnaesth. 2001; 87(3):400-405.

10. Maryam H, Amin J, Sedighe V, Vida A. Comparing the effects of peritonsillar infiltration of tramadol before and after the surgery on posttonsillectomy pain. Eur Arch Otorhinolaryngol. 2017;274(6):2521-2527.

11. Merkel S, Voepel-Lewis T, Shayevitz S, Malviya S. The FLACC: A behavioral scale for scoring postoperative pain in young children. Pediatr Nurs. 1997;23(3):293-297.

12. Willis MH, Merkel SI, Voepel-Lewis T, Malviya S. FLACC Behavioral Pain Assessment Scale: A comparison with the child's self-report. Pediatr Nurs. 2003;29(3):195-198.

13. Voepel-Lewis T, Merkel S, Tait AR, Trzcinka A, Malviya S. The reliability and validity of the Face, Legs, Activity, Cry, Consolability observational tool as a measure of pain in children with cognitive impairment. Anesth Analg. 2002;95(5):1224-1229.

14. Büttner W, Finke W. Analysis of behavioural and physiological parameters for the assessment of postoperative analgesic demand in newborns, infants and young children: A comprehensive report on seven consecutive studies. Paediatr Anaesth. 2000;10(3):303-318.

15. Karnchana $Y$, Suraseranivongse S, Pornsiriprasert S, et al. A comparison of postoperative pain scales in neonates. Br J Anaesth. 2006;97(4): 540-544.

16. Franck LS, Ridout D, Howard R, Peters J, Honour JW. A comparison of pain measures in newborn infants after cardiac surgery. Pain. 2011; 152(8):1758-1765.

17. Fieler M, Eich C, Becke $K$, et al. Metamizole for postoperative pain therapy in 1177 children: A prospective, multicentre, observational, postauthorisation safety study. Eur J Anaesthesiol. 2015;32(12):839-843.

18. Ambuel B, Hamlett KW, Marx CM, Blumer JL. Assessing distress in pediatric intensive care environments: The comfort scale. J Pediatr Psychol. 1992;17(1):95-109.

19. Reed MD, Yamashita TS, Marx CM, Myers CM, Blumer JL. A pharmacokinetically based propofol dosing strategy for sedation of the critically ill, mechanically ventilated pediatric patient. Crit Care Med. 1996; 24(9):1473-1481.

20. Blauer T, Gerstmann D. A simultaneous comparison of three neonatal pain scales during common NICU procedures. Clin J Pain. 1998;14(1): 39-47.

21. Van DijkM,DeBoerJB,KootHM, TibboelD, Passchier J, DuivenvoordenHJ. The reliability and validity of the COMFORT scale as a postoperative pain instrument in 0 to 3-year-old infants. Pain. 2000;84(2-3):367-377.

22. Broadman LM, Rice LJ, Hannallah RS. Testing the validity of an objective pain scale for infants and children. Anesthesiology. 2006;69 (Suppl):A770.

23. Alhashemi JA, Daghistani MF. Effects of intraoperative i.v. acetaminophen vs i.m. meperidine on post-tonsillectomy pain in children. $B r$ J Anaesth. 2006;96(6):790-795.

24. Wilson GAM, Doyle E. Validation of three paediatric pain scores for use by parents. Anaesthesia. 1996;51(11):1005-1007.

25. Ateş Y, Unal N, Cuhruk H, Erkan N. Postoperative analgesia in children using pre-emptive retrobulbar block and local anesthetic infiltration in strabismus surgery. Reg Anesth Pain Med. 1998;23(6):569-574.

26. Akkaya T, Aydin GB, Ersoy H, Ergil J, Karakoyunlu N, Polat R. Effect of two surgical circumcision procedures on postoperative pain: A prospective, randomized, double-blind study. J Pediatr Urol. 2015; 11(3):124.e1-124.e5. 
27. Hester NO, Foster R, Kristensen K. Measurement of pain in children: Generalizability and validity of the pain ladder and poker chip tool. Adv Pain Res Ther. 1990;15:79-84.

28. Matsota P, Papageorgiou-Brousta M, Kostopanagiotou G. Wound infiltration with levobupivacaine: An alternative method of postoperative pain relief after inguinal hernia repair in children. Eur J Pediatr Surg. 2007;17(4):270-274.

29. Rømsing J, Møller-Sonnergaard J, Hertel S, Rasmussen M. Postoperative pain in children: Comparison between ratings of children and nurses. J Pain Symptom Manage. 1996;11(1):42-46.

30. Whaley L, Wong D. Nursing Care of Infants and Children. $3^{\text {rd }}$ ed. St. Louis, MO: Mosby; 1987.

31. Wong DL, Baker CM. Pain in children: Comparison of assessment scales. Pediatr Nurs. 1988;14(1):9-17.

32. Tekelioglu UY, Apuhan T, Akkaya A, et al. Comparison of topical tramadol and ketamine in pain treatment after tonsillectomy. Paediatr Anaesth. 2013;23(6):496-501.

33. Hla TK, Hegarty M, Russell P, Drake-Brockman TF, Ramgolam A, von Ungern-Sternberg BS. Perception of pediatric pain: A comparison of postoperative pain assessments between child, parent, nurse, and independent observer. Paediatr Anaesth. 2014;24(11):1127-1131.

34. Knutsson J, Tibbelin A, von Unge M. Postoperative pain after paediatric adenoidectomy and differences between the pain scores made by the recovery room staff, the parent and the child. Acta Otolaryngol. 2006;126(10):1079-1083.

35. Beyer JE, Denyes MJ, Villarruel AM. The creation, validation, and continuing development of the Oucher: A measure of pain intensity in children. J Pediatr Nurs. 1992;7(5):335-346.

36. Jordan-Marsh M, Yoder L, Hall D, Watson R. Alternate oucher form testing: Gender, ethnicity, and age variations. Res Nurs Health. 1994; 17(2):111-118.

37. Onikul R, Bohaty B, Beyer JE, Young L, Jones L, Turner SB. The alternate forms reliability of the Oucher Pain Scale. Pain Manag Nurs. 2005:6(1):10-17.

38. Da Conceição MJ, Bruggemann Da Conceição D, Carneiro Leão C. Effect of an intravenous single dose of ketamine on postoperative pain in tonsillectomy patients. Paediatr Anaesth. 2006;16(9):962-967.

39. Hicks CL, von Baeyer CL, Spafford PA, van Korlaar I, Goodenough B. The Faces Pain Scale - Revised: Toward a common metric in pediatric pain measurement. Pain. 2001;93(2):173-183.

40. Tomlinson D, von Baeyer CL, Stinson JN, Sung L. A systematic review of faces scales for the self-report of pain intensity in children. Pediatrics. 2010;126(5):e1168-e1198.

41. Sun T, West N, Ansermino JM, et al. A smartphone version of the Faces Pain Scale - Revised and the Color Analog Scale for postoperative pain assessment in children. Paediatr Anaesth. 2015;25(12):1264-1273.

42. De Azevedo CB, Carenzi LR, De Queiroz DLC, Anselmo-Lima WT, Valera FCP, Tamashiro E. Clinical utility of PPPM and FPS-R to quantify post-tonsillectomy pain in children. Int J Pediatr Otorhinolaryngol. 2014;78(2):296-299.

43. Stinson JN, Kavanagh T, Yamada J, Gill N, Stevens B. Systematic review of the psychometric properties, interpretability and feasibility of selfreport pain intensity measures for use in clinical trials in children and adolescents. Pain. 2006;125(1-2):143-157.

44. Reeve RA, Champion DG, Bieri D, Ziegler JB, Addicoat L. The faces pain scale for the self-assessment of the severity of pain experienced by children: Development, initial validation, and preliminary investigation for ratio scale properties. Pain. 2003;41(2):139-150.

45. Hayes MH, Patterson DG. Experimental development of the graphic rating method. Psychol Bull. 1921;18:98-99.

46. Crichton N. Visual Analogue Scale (VAS). J Clin Nurs. 2001;10(5): 697-706.

47. Gagliese L, Weizblit N, Ellis W, Chan VWS. The measurement of postoperative pain: A comparison of intensity scales in younger and older surgical patients. Pain. 2005;117(3):412-420.
48. Kim MS, Choi HG, Park EK, Kim SY, Kim JH, Park B. Natural course of tonsillectomy pain: A prospective patient cohort study. Auris Nasus Larynx. 2018;45(3):508-513.

49. Jensen MP, Karoly P, Braver S. The measurement of clinical pain intensity: A comparison of six methods. Pain. 1986;27(1):117-126.

50. von Baeyer CL, Spagrud LJ, McCormick JC, Choo E, Neville K, Connelly MA. Three new datasets supporting use of the Numerical Rating Scale (NRS-11) for children's self-reports of pain intensity. Pain. 2009;143(3):223-227.

51. Voepel-Lewis T, Burke CN, Jeffreys N, Malviya S, Tait AR. Do 0-10 numeric rating scores translate into clinically meaningful pain measures for children? Anesth Analg. 2011;112(2):415-421.

52. Pagé MG, Katz J, Stinson J, Isaac L, Martin-Pichora AL, Campbell F. Validation of the numerical rating scale for pain intensity and unpleasantness in pediatric acute postoperative pain: Sensitivity to change over time. J Pain. 2012;13(4):359-369.

53. Kunimoto M, Kirnö K, Elam M, Karlsson T, Wallin BG. Neuro-effector characteristics of sweat glands in the human hand activated by irregular stimuli. Acta Physiol Scand. 1992;146(2):261-269.

54. Storm H. Changes in skin conductance as a tool to monitor nociceptive stimulation and pain. Curr Opin Anaesthesiol. 2008;21(6):796-804.

55. De Jesus JAL, Tristao RM, Storm H, Da Rocha AF, Campos D. Heart rate, oxygen saturation, and skin conductance: A comparison study of acute pain in Brazilian newborns. Conf Proc IEEE Eng Med Biol Soc. 2011;2011:1875-1879.

56. Ledowski T, Bromilow J, Paech MJ, Storm H, Hacking R, Schug SA. Monitoring of skin conductance to assess postoperative pain intensity. Br J Anaesth. 2006;97(6):862-865.

57. Storm $\mathrm{H}$. The capability of skin conductance to monitor pain compared to other physiological pain assessment tools in children and neonates. Pediatr Ther. 2013;3(4):168.

58. Ledowski T, Albus S, Stein J, MacDonald B. Skin conductance for monitoring of acute pain in adult postoperative patients: Influence of electrode surface area and sampling time. J Clin Monit Comput. 2011;25(6):371-376.

59. Logier R, Jeanne M, De Jonckheere J, Dassonneville A, Delecroix M, Tavernier B. PhysioDoloris: A monitoring device for analgesia/nociception balance evaluation using heart rate variability analysis. 2010 Annu Int Conf IEEE Eng Med Biol Soc EMBC'10. 2010:1194-1197.

60. Parker N, Ledowski T, Tiong WS, Lee C, Wong B, Fiori T. Analgesia nociception index: Evaluation as a new parameter for acute postoperative pain. Br J Anaesth. 2013;111(4):627-629.

61. Butruille L, De Jonckheere J, Marcilly R, et al. Development of a pain monitoring device focused on newborn infant applications: The NeoDoloris project. IRBM. 2015;36(2):80-85.

62. Faye PM, De Jonckheere J, Logier R, et al. Newborn infant pain assessment using heart rate variability analysis. Clin J Pain. 2010;26(9):777-782.

63. Yaster M, Traystman RJ. Multimodal analgesia in children. Eur J Anaesthesiol. 2010;27(10):851-857.

64. Walker SM. Pain after surgery in children: Clinical recommendations. Curr Opin Anaesthesiol. 2015;28(5):570-576.

65. Vittinghoff $M$, Lönnqvist PA, Mossetti V, et al. Postoperative pain management in children: Guidance from the pain committee of the European Society for Paediatric Anaesthesiology (ESPA Pain Management Ladder Initiative). Paediatr Anaesth. 2018;28(6):493-506.

66. Lam KK, Kunder S, Wong J, Doufas AG, Chung F. Obstructive sleep apnea, pain, and opioids: Is the riddle solved? Curr Opin Anaesthesiol. 2016;29(1):134-140.

67. American Society of Anesthesiologists Task Force on Acute Pain Management. Practice guidelines for acute pain management in the perioperative setting. Anesthesiology. 2012;116(2):248-273.

68. Cowen R, Stasiowska MK, Laycock H, Bantel C. Assessing pain objectively: The use of physiological markers. Anaesthesia. 2015;70(7): 828-847. 